\title{
Scleral and Body Hyperpigmentation in Disseminated Tuberculosis with Adrenal Insufficiency (Addison's Disease)
}

\section{Muzamil Latief ${ }^{1}$, Waseem Raja ${ }^{2^{*}}$, Manzoor Parry ${ }^{1}$ and Ravi Rao ${ }^{1}$}

${ }^{1}$ Department of Internal Medicine, University Ambala, Maharishi Markandeshwar, Haryana

${ }^{2}$ Department of Internal Medicine, Sher-i-Kashmir Institute of Medical Sciences, Jammu \& Kashmir, India

"Corresponding author: Waseem Raja, Department of Internal Medicine, Sher-i-Kashmir Institute of Medical Sciences, Jammu \& Kashmir, India, Tel: +918222800676; E-mail: drwaseem.mw@gmail.com

Received date: February 24, 2016; Accessed date: March 02, 2016; Published date: March 11, 2016

Copyright: (c) 2016 Latief M, et al. This is an open-access article distributed under the terms of the Creative Commons Attribution License, which permits unrestricted use, distribution, and reproduction in any medium, provided the original author and source are credited.

\section{Clinical Image}

A 25 years old gentleman was diagnosed with Pulmonary Tuberculosis 1 year back and started on Anti Tuberculosis Treatment (ATT) 4 Drugs (Isoniazid, Rifampin, Pyrazinamide and Ethambutol). He took these medications for a period of 6 weeks and stopped the medication on his own. He never returned to any healthcare facility until he presented to us with complaints of weight loss for last 6 months, progressive skin hyperpigmentation and nausea for 4 weeks before presenting to us. On presentation, there was diffuse hyperpigmentation of whole body including buccal mucosa, tongue and sclera (Figures 1-3). He was in hypotension with tachycardia. Investigations revealed hyponatremia with random serum cortisol 8 $\mathrm{nmol} / \mathrm{L}$ and Post ACTH stimulation, cortisol levels at 30 minutes and 60 minutes were $<11 \mathrm{nmol} / \mathrm{L}$. Serum ACTH levels were high. Abdominal Imaging revealed bilateral Adrenal Enlargement. Patient was started on IV fluids and IV steroids (Hydrocortisone $50 \mathrm{mg} 6$ hourly) and Anti-Tuberculosis Treatment (Isoniazid, Rifampin, Pyrazinamide, Ethambutol and Streptomycin). His hemodynamic parameters improved during hospital stay, nausea and anorexia settled. Subsequently patient was discharged on oral steroids Hydrocortisone $20 \mathrm{mg}$ twice a day and Fludricortisone $100 \mathrm{mcg} /$ day and made to continue ATT. Patient is doing well on follow up.

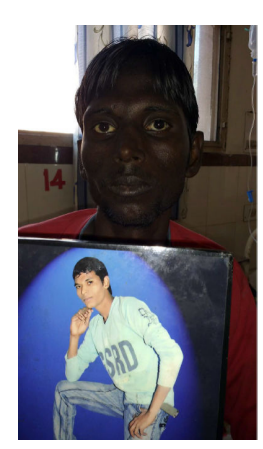

Figure 1: Patient holding his own photograph taken earlier.

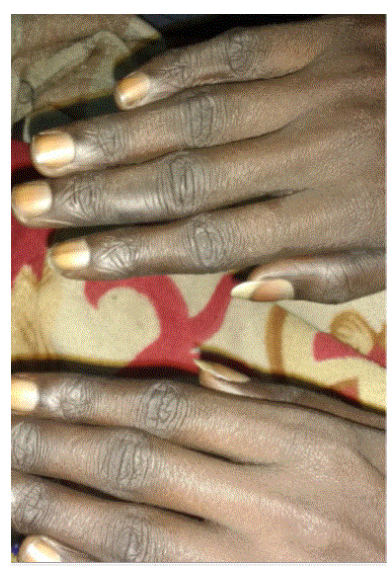

Figure 2: Hyper pigmented Knuckles.

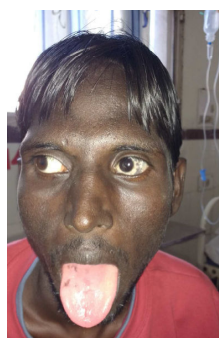

Figure 3: Scleral, Tongue and Facial pigmentation. 